\title{
Water balance of rice plots under three different cultivation methods: first season results
}

\author{
Enrico Antonio Chiaradia, ${ }^{1}$ Arianna Facchi, ${ }^{1}$ Olfa Gharsallah, ${ }^{1}$ Marco Romani, ${ }^{2}$ \\ Gian Battista Bischetti, ${ }^{1}$ Claudio Gandolfi ${ }^{1}$ \\ ${ }^{1}$ DiSAA, Università degli Studi di Milano, Milano, Italy; ${ }^{2}$ CRR, Ente Nazionale Risi, Castello \\ d'Agogna (PV), Italy
}

\begin{abstract}
In the last years rice cultivation methods have been the object of an intense research activity aiming to implement new irrigation methods in addition to traditional flooding, in order to reduce water use. This change has concerned also the traditional paddy-rice territories of the north-west of Italy, where rice has been traditionally cultivated as flooded and where paddy fields are a strong landscape landmark and represent a central feature in the Italian and European network for nature protection. The new techniques introduced in these territories consist in a dry seeding followed by field flooding after about one month (third-fourth leaf), and in a full aerobic cultivation with intermittent irrigations, similarly to standard irrigated crops. This paper presents the results obtained after the first year of a monitoring activity carried out at the Ente Nazionale Risi Experimental Station of Castello d'Agogna-Mortara (PV, Italy), where the main terms of water balance have been measured or estimated during the whole crop season. Because there is a substantial lack of data concerning the water balance related to the new water management techniques, the data are of wide interest despite this study covered only one season. The results here presented show that dry seeding-delayed flooding method
\end{abstract}

Correspondence: Gian Battista Bischetti, DiSAA via Celoria 2 , 20133 Milano, Italy.

Tel. +39.02.50316904 - Fax: +39.02.50316911.

E-mail: bischetti@unimi.it

Key words: water balance, rice, soil hydrology.

Contributions: the authors contributed equally.

Conflict of interests: the authors declare no potential conflict of interests Funding: the work was supported by Regione Lombardia under the grants "Fondo per la promozione di accordi istituzionali, "Project "BIOGESTECA" Piattaforma di biotecnologie verdi e di tecniche gestionali per un sistema agricolo ad elevata sostenibilità ambientale Project, n. 4779, 14/05/2009.

Acknowledgments: the authors wish to thank Daniele Ferrari, Ezio Naldi, Gianluca Beltarre and its staff for the field assistance.

(C) Copyright E.A. Chiaradia et al., 2013

Licensee PAGEPress, Italy

Journal of Agricultural Engineering 2013; XLIV(s2):e159

doi:10.4081/jae.2013.s2.e159

This article is distributed under the terms of the Creative Commons Attribution Noncommercial License (by-nc 3.0) which permits any noncommercial use, distribution, and reproduction in any medium, provided the original author(s) and source are credited. required a rather similar amount of water respect to the traditional flooding method (2200 $\mathrm{mm}$ and $2491 \mathrm{~mm}$, respectively), whereas the aerobic technique required one order of magnitude less water (298 $\mathrm{mm}$ ), also due to the very shallow depth of the surface aquifer. Since evapotranspiration was nearly the same for the three methods (578 $\mathrm{mm}, 555 \mathrm{~mm}$, and $464 \mathrm{~mm}$, respectively for traditional flooded, dry seeding-delayed flooding and aerobic methods), percolation was very high in the case of the two flooded methods and very limited in the case of the aerobic cultivation with intermittent irrigations. These results suggest that, if the aerobic cultivation of rice represents a highly effective water-saving technique at the field scale, at the same time if applied on a large scale in traditional paddy areas, as the north-west of Italy, it could be a potential threat for groundwater dynamics, due to the dramatic decrease of groundwater recharge, and in general for traditional landscape conservation and nature protection.

\section{Introduction}

Rice is one of the most extended cultivations around the world and represents the main food for millions of people. As it requires a larger amount of water compared with other crops (e.g. Feng et al. 2007), it is at risk of water scarcity (Tuong and Bouman 2003) and represents an important target for reductions in water use worldwide. In South and Southeast Asia, for example, Tuong and Bouman (2003) estimate that by 2025 approximately 15 million hectares may experience "physical water scarcity" and 22 million hectares "economic water scarcity".

This has stimulated the application of new water-saving methods for rice cultivation, consisting of wetting and drying fields (Bouman and Tuong, 2001; Belder et al., 2004), continuous soil saturation (Borell et al., 1997), dry seeding (Tabbal et al., 2002) and aerobic cultivation as in standard irrigated crops (Bouman et al., 2005). The amounts of water saved by implementing the different water-saving systems vary greatly with climate, soil type and hydrological conditions (Cabangonet al., 2004; Li, 2001; Mao, 1993; Bouman et al., 2005; Yang et al., 2005) and general guidelines cannot yet be drawn.

Although in Italy rice cultivation is only $0.2 \%$ of the world's surface (FAOSTAT data for 2011), in some areas it represents a relevant crop both in terms of cultivated land and economic value, as well as from an environmental and landscape perspective.

In Piedmont and western Lombardy, in particular, rice cultivation extends for more than 227,000 hectares (over $92 \%$ of the rice cultivated surface in Italy and about a half in Europe; Ente Nazionale Risi and FAOSTAT data for 2011), representing nearly $10 \%$ of the total value of the agriculture sector. In these territories, moreover, paddy rice fields have been one of the main landscape markers from centuries, and one of the main wetland in the north-western part of Italy where it represents a keystone in the European protection policy for wild bird migratory species. The paddy fields of Piedmont and Lombardy, in fact, are a 
portion of the European ecological network NATURA 2000 and on the official list of the European Special Protection Areas (Habitat Directive, 92/43/EEC), which together with the Birds Directive (79/409/EEC) forms the cornerstone of Europe's nature conservation policy.

In such territories water has never been scarce, but due to increasing competition from new water uses (industry, hydropower, dilution of chemicals in natural water bodies, etc.) and the European Water Framework Directive, which requires more efficient water use in agriculture, the traditional flooded rice cultivation is being questioned and some water-saving methods are appearing. In particular dry seedling followed by delayed flooding (after approximately one month, at thirdfourth leaf emission) now represents approximately one third of the whole cultivated area in Piedmont and Lombardy, whereas full aerobic cultivation is gaining increasing popularity.

Studies aiming to quantify the reduction of water inputs as a consequence of the application of water-saving techniques are increasing (Bouman et al., 2005; Feng et al., 2007; Luo et al., 2009; Alberto et al., 2011), but they are mainly carried out in Asian regions where pedo-climatic conditions and cultivation methods are very different from Europe and Italy. Moreover, most of these studies lack on analysis of the hydrological processes on which the water requirement reduction is due (transpiration, evaporation, percolation, etc.) and the dynamics of water fluxes related to irrigation methods is still poorly investigated and understood (Bouman et al., 2007). As a consequence, the scalingup of the results obtained so far, from field to larger spatial scales, cannot be used to analyse the potential effects of extensive adoption of the new techniques on water requirements at the regional scale and on environment and landscape characteristics, as well as on irrigation service organization.

This paper, contributing to fill such a gap, presents results obtained after the first year of a monitoring activity carried out on three experimental plots, cultivated following one of the three mentioned irrigation techniques adopted (or being adopted) in Piedmont and Lombardy's traditional rice cultivation areas.

\section{Materials and methods}

Field experiments were conducted at the Ente Nazionale Risi Rice Research Centre's experimental station located in Castello d'AgognaMortara (PV, Italy), within a traditional rice cultivated area. Three on a total of six experimental plots have been instrumented for water fluxes and water storage monitoring (Figure 1).

In order to characterise the soil, five profiles were dug outside of the experimental plots and 112 observations (at three depths each) were carried out inside the plots, according to a regular grid, by a bucket auger. Results led to a detailed pedological map (Figure 2) that guided the positioning of tensiometers and water content probes. Fundamentally three soil type were identified (A, B, C), plus a transitional type between A and C (AC).

In type A, classified as "Aeric Epiaquept" or "Aeric Epiaqualf" (Soil Taxonomy, USDA, 2010), three horizons were identified: Apg (0-35 cm, $1.4-1.5 \mathrm{~g} \mathrm{~cm}^{-3}$, silt loam), B acting as plough pan or hard pan $(35-75 \mathrm{~cm}$, 1.5-1.6 $\mathrm{g} \mathrm{cm}^{-3}$, silt loam) and subsoil (>75 cm, 1.4-1.5 $\mathrm{g} \mathrm{cm}^{-3}$, sand). Type B is similar to type A (silt loam) but the first horizon appeared darker and thicker. In type C, classified as "Aquic Ustipsamment", four horizons can be identified: Apg1 (0-35 cm, 1.5-1.6 g cm ch $^{-3}$ loam), Apg2 representing the hard pan (35-50 cm, 1.6-1.7 $\left.\mathrm{g} \mathrm{cm}^{-3}, \mathrm{loam}\right), \mathrm{B}$ and $\mathrm{C}$ (>50 cm, 1.4-1.5 $\mathrm{g} \mathrm{cm}^{-3}$, sand).

Each plot (approximately $20 \mathrm{~m}$ x $80 \mathrm{~m}$ ) has been cultivated under one of the three cited irrigation methods (two replicates each): i) traditional flooding, ii) dry seeding and delayed flooding, and iii) aerobic cultivation (noted in the course of the paper- see Figure 1 and 2- as T2, $\mathrm{T} 1$ and T3, respectively). The land was prepared in all plots by ploughing and harrowing under dry conditions for all the treatments.

Flooded cultivation consisted of flooding the fields just after tilling, without any puddling, and seeding in water. Few drying periods were done to allow weed control operations and fertilization until the final drying (06/09) before harvesting (21/09).

Dry seeding and delayed flooding consisted of making all tillage operations and seeding before any field flooding, that was done approximately after one month when the third or the fourth leaf appears. After the first flooding, fields were dried only once (11/07-14/7 ) to allow rice blast control operations and fertilization, and then flooded again until the final drying (06/09) required for harvesting (21/09).

Aerobic method consisted of rice cultivation like standard irrigated crops, maize for example, providing irrigation when necessary.

The seeded rice cultivar was Gladio type for all the plots, and sowing dates were 15/05 for aerobic (T3) and dry seeding-delayed flooding (T1) methods, and 28/05 for the traditional flooded irrigation (T2).

No transplantation have been adopted in any treatment as such practice was abandoned in Europe from several decades. All plots were kept free from weeds, pests, and diseases, by application of chemicals.

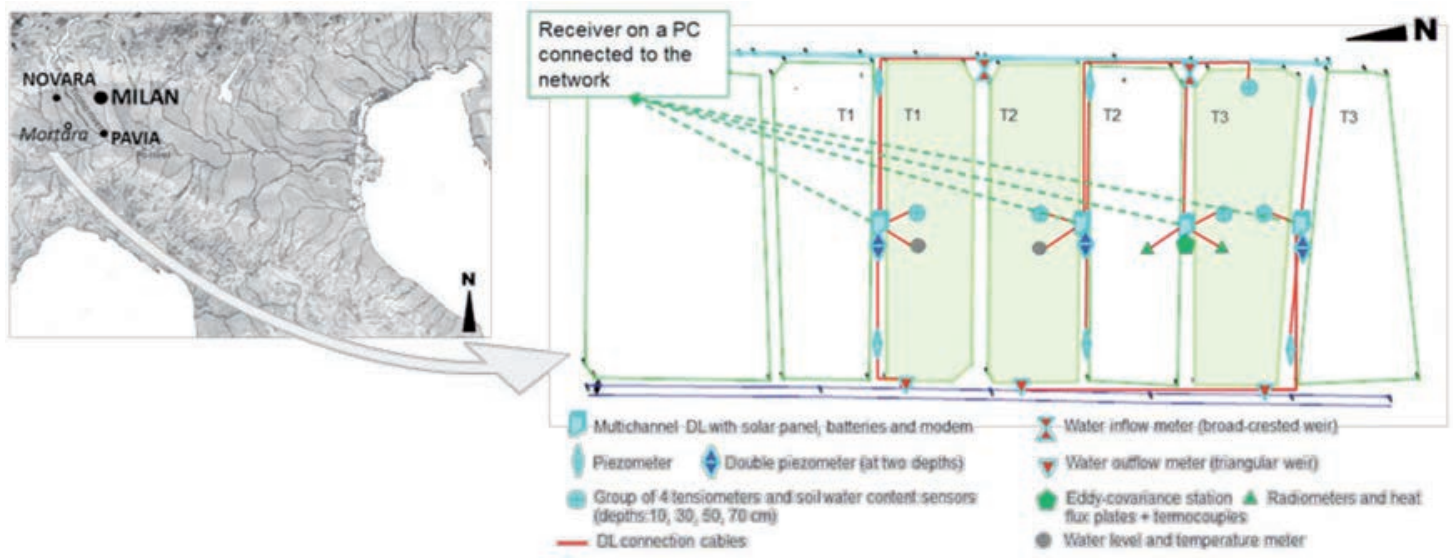

Figure 1. Location of the experimental site and plots with the installed instruments positions. 
Aerobic treatment was irrigated nine times during the season (approximately every 7-10 days), with the last irrigation approximately one month before harvesting (24/08) that was done on 21/09.

Continuous measures and records were made for several variables. For all the treatments: inflow and outflow discharge, ground water level by $1.5 \mathrm{~m}$ screen piezometers placed along the levees at the two extremity of plots with their bottom at $2.3 \mathrm{~m}$; a couple of a $0.1 \mathrm{~m}$ screen piezometer at the middle of levees, with bottom at $1.0 \mathrm{~m}$ and $2.4 \mathrm{~m}$, were also placed. In T1 and T2 ponded water depth was also monitored, whereas in T3 plot (aerobic method), three tensiometer groups were installed considering the three soil types. Each tensiometer group was coupled with a multiple depth sensor probe for water content measurements (EnviroSCAN Sentek) placed aside each group. A probe for water content monitoring and four tensiometers were also installed in T1 plot, and removed just before plot flooding.

Standard meteorological variables (rainfall, radiation, temperature, humidity, wind speed, wind direction) were measured on an hourly time step over a grass coverage by a station of the regional meteorological network (ARPA), located in the ENR centre at a distance of about $100 \mathrm{~m}$ from the experimental fields.

In addition, an eddy covariance station was installed on the edge between the traditional flooding and the aerobic rice treatments, but its data were not used for this work (for more details about the eddy covariance system and results see Facchi et al., 2013). Details on the experimental design and the installed instrumentation is presented in a companion paper (Chiaradia et al., 2013).

In addition to the continuous automatic monitoring, some periodic measurement campaigns (11 dates) were carried out to monitor the crop growth (leaf area index, crop height, depth of roots).

Irrigation (I), outflow (0) and rainfall (R) were directly measured, and summed for the periods covering the crop growth from seeding (or flooding in the case of the traditional flooding method) to harvesting. Evaporation from soil $\left(\mathrm{E}_{\mathrm{s}}\right)$, from the water surface during the flooding periods $\left(\mathrm{E}_{\mathrm{a}}\right)$ and transpiration (T) from the canopy, were estimated by direct application of Penman-Monteith type equations at hourly time steps for all the three irrigation treatments. As some of the requested meteorological data were not available, the adjustments suggested by Rana and Katerji (2009) relating meteorological data monitored over a standard grass cover to those expected over a rice canopy, were adopt- ed. For more detail on ET estimation see Facchi et al. (2013).

Soil water content at the beginning and at the end of the cropping season were obtained from each treatment from the available soil water potential and soil water content measurements.

Finally, fluxes at the bottom of the hard pan (percolation P plus capillary rise CR) have been obtained as the closure term of water budget in agreement with other authors (e.g. Bouman et al., 2005).

Water application efficiency (AE) can be calculated as (Bouman et al., 2005):

$$
A E=\frac{E T}{I+R}
$$

In Piedmont and Lombardy systems, however, outflow cannot be considered a loss as it is used to feed downstream fields and AE can be calculated as:

$$
A E^{\prime}=\frac{E T}{I+R-O}
$$

\section{Results and discussion}

The water balance for the three plots is reported in Table 1. The irrigation provided to $\mathrm{T} 1$ is greater than the one provided to $\mathrm{T} 2$, but the same can be observed for the outflow discharge. In this way the water actually provided by irrigation in T1 is $88 \%$ of T2 amount. This can be essentially due to percolation and water evaporation in the first month when T2 was flooded and T1 was not. In the case of T3, the water provided by irrigation is $12 \%$ of $\mathrm{T} 2$ and $14 \%$ of $\mathrm{T} 1$.

The actual water consumption due to evapotranspiration of the crop under the three different treatments, on the contrary, is approximately the same for T1 and T2 and slightly less in T3 (96\% and 80\% of T2 for $\mathrm{T} 1$ and T3 respectively). Looking at the single components of ET, it can be noted that transpiration is nearly the same (104\% and $91 \%$ of T2 for $\mathrm{T} 1$ and T3 respectively), whereas the major difference between T3 and the other two treatments depends, as obvious, on evaporation amounts. In T3 water evaporation is null and in T1 it is two thirds of T2 as a consequence of the delay in flooding. The smaller value of transpiration in

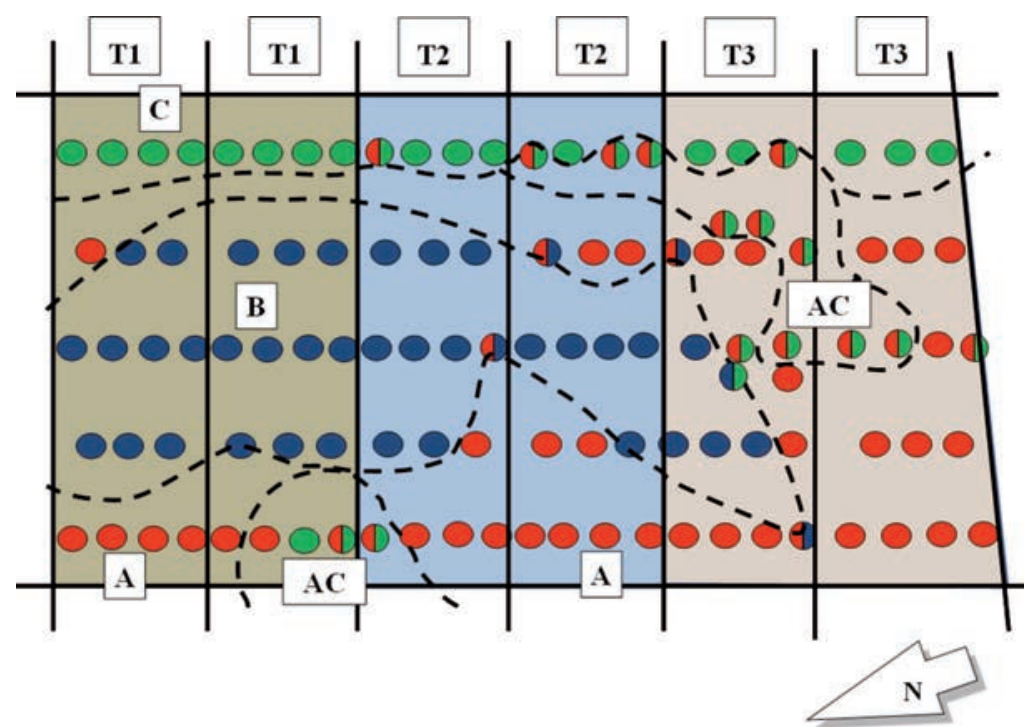

Figure 2. Soil type distribution in the experimental plots. 
T3 can be ascribed to lower values of LAI during the season as showed in Figure 3a.

In terms of daily trend during the season, in the first period ET for T1 treatment was equal to aerobic (T3), whereas after flooding it became similar to the T2 treatment (Figure $3 \mathrm{~b}$ ).

The fact that the closure term represents vertical fluxes (percolation and capillary rise), and that seepage between plots with different irrigation treatments can be excluded.

It can be noted that, as expected, high percolation values concerns the traditional flooded treatment and secondarily the delayed flood one. For the aerobic cultivation the net flux is almost null, indicating that in this treatment the percolation flux basically equates the capillary rise, making groundwater recharge negligible. A better exploration of this issue will be addressed by applying mathematical simulation models to the experimental datasets.

The EA' values, as a consequence, are a little greater than $20 \%$ in flooded and delayed flooded cultivation and close to $100 \%$ for aerobic rice.

Table 1. Seasonal water budget for the three treatments (different rainfall volumes are due to small difference in plot size).

\begin{tabular}{lccc} 
Term of water balance & $\begin{array}{c}\text { Flooded } \\
\text { cultivation } \\
\text { (T2) }\end{array}$ & $\begin{array}{c}\text { Dry } \\
\text { seedling } \\
\text { (T1) }\end{array}$ & $\begin{array}{c}\text { Aerobic } \\
\text { cultivation } \\
\text { (T3) }\end{array}$ \\
Season duration (days) & 120 & 122.0 & 122.0 \\
Rainfall (mm) & 133 & 133 & 133 \\
\hline Irrigation (mm) & 4728 & 5322 & 884 \\
Plot outflow (mm) & -2237 & -3123 & -585 \\
\hline Evapotranspiratipon (mm) & -691 & -678 & -568 \\
Soil evaporation (mm) & -40 & -37 & -67 \\
Water evaporation (mm) & -100 & -67 & - \\
Transpiration (mm) & -551 & -574 & -501 \\
Soil (40 cm) storage variation (mm) & -10 & -10 & -28 \\
\hline Percolation and capillary rise (mm) & -2056 & -1788 & 18 \\
AE' (\%) & 22 & 24 & 1.08
\end{tabular}

\section{Conclusions}

The results of this study, although preliminary, indicate that rice cultivated in aerobic conditions has a great potentiality as a water-saving technique. The amount of water required during the season, in fact, is of one order of magnitude less than traditional flooded and dry seedingdelayed flooding methods, which required approximately the same quantity of water. The delay in flooding resulted in saving less than 300 $\mathrm{mm}$ (approx. 10\%) compared to traditional flooding.

The rate of water saving is considerably higher than those obtained in Asian experiments (Bouman et al., 2005; Feng et al., 2007), and in our interpretation this is mainly due to a greater attention given in our experiments to aerobic rice irrigation and/or to difference in cultivation, as for example doing or not puddling, and groundwater levels, which can significantly affect the percolation rate.

The amount of evapotranspiration, on the contrary, is comparable to the values reported in other studies (Singh et al., 2006; Alberto et al., 2011). The differences can be ascribed, besides climate and irrigation management, to the length of the agricultural season, that in the case study was quite short (about 120 days). ET was found to be approximately the same for flooded and dry seeding irrigation methods (691 and $678 \mathrm{~mm}$ respectively) and $12-14 \%$ less for aerobic rice (568 $\mathrm{mm}$ ).

In conclusion, the results obtained in the first year of experimentation suggest that water saving related to aerobic cultivation of rice fundamentally strongly reduces the vertical flux towards the water table, affecting the groundwater recharge. If this undoubtedly is considerable in terms of irrigation efficiency at the field scale, however, a massive conversion of the traditional irrigation methods on a regional scale must be properly evaluated, as it could dramatically impact on groundwater resources and on landscape conservation and nature protection.

\section{References}

Alberto MCR, Wassmann R., Hirano T. , Miyata A. , Hatano R., Kumar A., Padre A., Amante M. 2011. Comparisons of energy balance and evapotranspiration between flooded and aerobic rice fields in the Philippines. Agric. Water Manag. 98: 1417- 1430

Belder P., Bouman B.A.M., Cabangon R., Lu G., Quilang E.J.P., Li Y.,
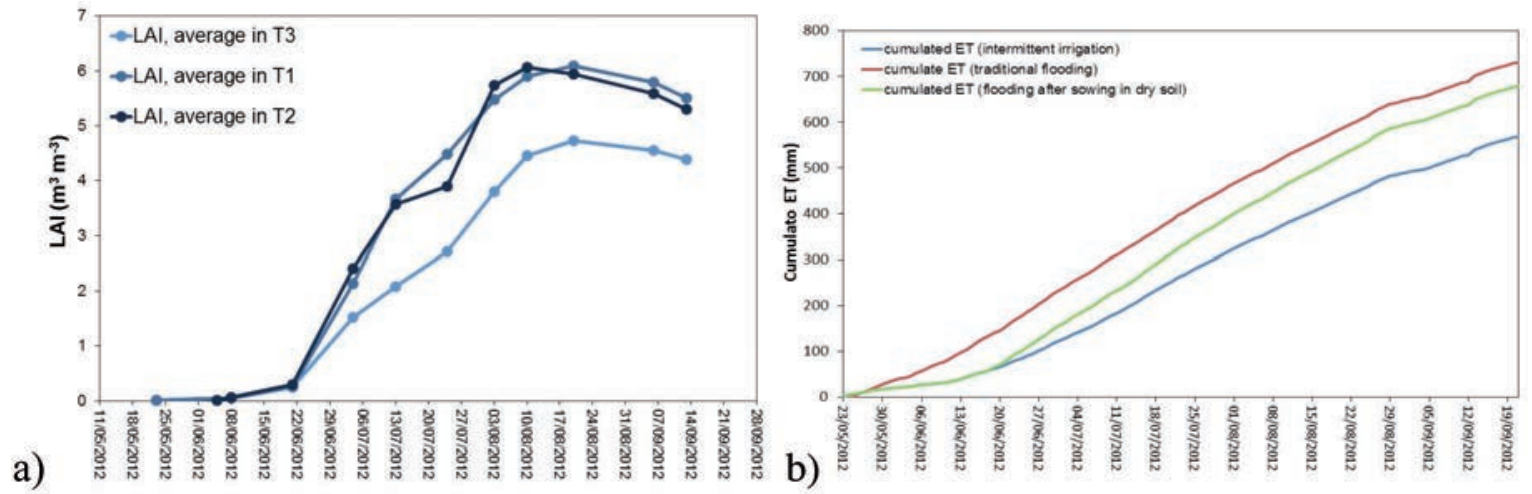

Fig. 3. a) the leaf area index values during the season (measured by a LP-80 AccuPAR Ceptometer) shows that aerobic rice produced a smaller amount of aboveground biomass with respect to the other two treatments, affecting the transpiration term; b) cumulated ET values during the season simulated by Penman-Monteith type models show that delayed flooding treatment behave exactly like the aerobic rice in the first stage of the season and as traditional flooded rice in the second. 
Spiertz J.H.J., Tuong T.P. 2004. Effect of water-saving irrigation on rice yield and water use in typical lowland conditions in Asia. Agric. Water Manage. 65: 193-210.

Borell A., Garside A., Fukai S. 1997. Improving efficiency of water for irrigated rice in a semi-arid tropical environment. Field Crops Res. 52: 231-248.

Bouman B.A.M., Tuong T.P. 2001. Field water management to save water and increase its productivity in irrigated rice. Agric. Water Manage. 49: 11-30.

Bouman B.A.M., Feng L., Tuong T.P., Lu G., Wang H., Feng Y. 2007. Exploring options to grow rice using less water in northern China using a modelling approach: II. Quantifying yield, water balance components, and water productivity. Agric. Water Manag. 88: 23-33

Cabangon R.J., Tuong T.P., Castillo E.G., Bao L.X., Lu G., Wang G.H., Cui L., Bouman B.A.M., Li Y., Chen C., Wang J. 2004. Effect of irrigation method and $\mathrm{N}$-fertilizer management on rice yield, water productivity and nutrient-use efficiencies in typical lowland rice conditions in China. Paddy Water Environ. 2: 195-206.

Chiaradia E.A., Ferrari D., Bischetti G.B., Facchi A., Gharsallah 0., Gandolfi C. 2013. Monitoring water fluxes in rice plots under three different cultivation methods, 10th AIIA Conference: "AIIA13 Horizons in agricultural, forestry and biosystems engineering", Viterbo (Italy), September 8-12, 2013.

Ente Nazionale Risi 2013, Data base delle superfici coltivate (Data base of cultivated extension), http://www.enterisi.it (Accessed: May 2013)

Facchi A., Gharsallah 0., Chiaradia E.A., Bischetti G.B., Gandolfi C. 2013. Monitoring and modelling evapotranspiration in flooded and aerobic rice fields, Four Decades of Progress in Monitoring and Modeling of Processes in the Soil-Plant-Atmosphere System: Applications and Challenges, Procedia Environmental Sciences.

FAOSTAT 2013. Food and Agriculture Organization. FAOSTAT on-line electronic database. http://faostat.fao.org/site/291/default.aspx (accessed: May 2013)
Feng L., Bouman B.A.M., Tuong T.P., Cabangon R.J., Li Y., Lu G., Feng Y. 2007. Exploring options to grow rice using less water in northern China using a modelling approach: I. Field experiments and model evaluation Agricultural Water Management, 88: 1-13

Li Y. 2001. Research and practice of water saving irrigation for rice in China. In: Barker, R., Loeve, R., Li, Y., Tuong, T.P. (Eds.), Proceedings of the International Workshop on Water-saving Irrigation for Rice, March 23-25, Wuhan, China. International Water Management Institute, Colombo, Sri Lanka, pp. 135-144.

Luo Y. Khan S., Cui Y., Peng S. 2009, Application of system dynamics approach for time varying water balance in aerobic paddy fields. Paddy Water Environ. 7:1-9

Mao Z. 1993. Study on evaluation of irrigation performance in China. In: Proceedings of the Asian Regional Symposium on Maintenance and Operation of Irrigation/Drainage Scheme and Improved Performance, Beijing, China, pp. 6-35.

Rana G., Katerji N. 2009. Operational model for direct determination of evapotranspiration for well watered crops in Mediterranean region. Theor. Appl. Climatol., 97: 243-253.

Singh R., van Dam J.C., Feddes R.A. 2006. Water productivity analysis of irrigated crops in Sirsa district, India. Agricultural Water Management, 82: 253-278

Tabbal D.F., Bouman B.A.M., Bhuiyan S.I., Sibayan E.B., Sattar M.A. 2002. On-farm strategies for reducing water input in irrigated rice; case studies in the Philippines. Agric. Water Manage. 56:93-112.

Tuong T.P., Bouman B.A.M. 2003. Rice production in water-scarce environments. In: Kijne, J.W., Barker, R., Molden, D. (Eds.), Water Productivity in Agriculture: Limits and Opportunities for Improvement. CABI Publishing, UK, pp. 53-67

Yang X., Bouman B.A.M., Wang H., Wang Z., Zhao J., Chen B., 2005. Performance of temperate aerobic rice under different water regimes in North China. Agric. Water Manage. 74, 107-122. 